\title{
La Revista en la Web
}

\section{The Journal on the Web}

Nuestra revista tiene más de 50 años de existencia. Durante este largo periodo hemos aparecido en formato tradicional de papel, a lo que en los últimos años se ha agregado un formato electrónico adosado a la página web corporativa de la Sociedad. Además, estamos en ISI, SciELO, Google, EBSCO Publishing y otras bases electrónicas de revistas científicas.

Hace algunos meses hemos creado una página web propia de la publicación, con lo que nos hemos transformado en una revista digital. Ello evidentemente significa una actualización acorde con los tiempos, con múltiples ventajas de todo tipo. Esta base digital está en perfeccionamiento permanente y muy luego podremos acceder a ella sin problemas incluso desde nuestros teléfonos móviles. ¿Qué nivel de aceptación hemos tenido en estos primeros meses?

La página tiene la capacidad de medir las visitas a su contenido, lo que es monitoreado por la empresa que la administra. Según esta información, hemos asistido a un aumento progresivo muy interesante e inesperado. Así durante el mes de julio la revista digital tuvo alrededor de 700 visitas directas y más de 20.000 visitas indirectas. Llamamos indirectas a aquellas en que su contenido es extraído a través de otra base de datos en la que estamos indexados. Los accesos a nuestro contenido digital han sido medidos como provenientes de los cinco continentes, lo que se traduce también en que estamos recibiendo artículos para eventual publicación de lugares inesperados, tales como China, Georgia o Angola.

En una primera etapa, se ha conservado la publicación en papel, la que ha sido distribuida como de costumbre a todos los socios y entidades correspondientes. Estamos entrando a la segunda etapa programada, en la cual predominará la forma digital, asi la forma impresa se hará llegar sólo a quienes lo soliciten; hace algunos meses se realizó una encuesta entre los socios preguntando por las preferencias al respecto, por lo que ya tenemos una primera mirada. Es importante que quienes asi lo deseen y no contestaron la encuesta, se comuniquen con nuestra secretaria y se lo hagan saber. La no comunicación de parte del socio, nos hará asumir que la forma digital le es suficiente y no necesita recibir la revista en papel.

Podemos decir, con legítima satisfacción, que estamos en el camino de la optimización de la comunicación en ciencia y tecnología. Una vez más, solicitamos a nuestros socios y a nuestros usuarios del resto del mundo, que nos envién lo mejor de su producción académica y cientifica, pues pueden estar seguros de que ella será conocida en todas partes.

Dr. Julio Yarmuch G. Editor 